\title{
Quantifying the learning curve for pulmonary thromboendarterectomy
}

\author{
Smita Sihag ${ }^{1,4^{*}} \mathbb{D}$, Bao Le ${ }^{1}$, Alison S. Witkin², Josanna M. Rodriguez-Lopez ${ }^{2}$, Mauricio A. Villavicencio ${ }^{3}$, \\ Gus J. Vlahakes ${ }^{3}$, Richard N. Channick ${ }^{2}$ and Cameron D. Wright ${ }^{1}$
}

\begin{abstract}
Background: Pulmonary thromboendarterectomy (PTE) is an effective treatment for chronic thromboembolic pulmonary hypertension (CTEPH), but is a technically challenging operation for cardiothoracic surgeons. Starting a new program allows an opportunity to define a learning curve for PTE.

Methods: A retrospective case review was performed of 134 consecutive PTEs performed from 1998 to 2016 at a single institution. Outcomes were compared using either a two-tailed t-test for continuous variables or a chi-squared test for categorical variables according to experience of the program by terciles ( $T$ ).

Results: The 30-day mortality was $3.7 \%$. The mean length of hospital stay, length of ICU stay, and duration on a ventilator were 12.6 days, 4.6 days, and 2.0 days, respectively. The mean decrease in systolic pulmonary artery pressure (sPAP) was $41.3 \mathrm{mmHg}$. Patients with Jamieson type 2 disease had a greater change in mean sPAP than those with type 3 disease $(p=0.039$ ). The mean cardiopulmonary bypass time was $180 \mathrm{~min}(T 1-198 \mathrm{~min}, \mathrm{T3}-159 \mathrm{~min}, p=<0.001)$, and the mean circulatory arrest time was $37 \mathrm{~min}($ T1-44 min, T3-31 min, $p<0.001)$. Plotting circulatory arrest times as a running sum compared to the mean demonstrated 2 inflection points, the first at 22 cases and the second at 95 cases.

Conclusions: PTE is a challenging procedure to learn, and good outcomes are a result of a multi-disciplinary effort to optimize case selection, operative performance, and postoperative care. Approximately 20 cases are needed to become proficient in PTE, and nearly 100 cases are required for more efficient clearing of obstructed pulmonary arteries.
\end{abstract}

Keywords: Pulmonary thromboendarterectomy, Outcomes, Learning curve

\section{Background}

Chronic thromboembolic pulmonary hypertension (CTEPH) is a relatively rare disease affecting less than $5 \%$ of patients subsequent to an acute pulmonary embolism [1]. It is characterized by pulmonary hypertension resulting from pulmonary vascular obstruction which leads to progressive right ventricular dysfunction. Riedel et al. reported that patients with mean pulmonary artery pressures greater than $30 \mathrm{mmHg}$ have only a 30\% 5-year survival, and in patients with mean PAPs greater than $50 \mathrm{mmHg}$, 5-year survival further decreases to as low as $10 \%$ [2]. Medical therapy is palliative and can mitigate symptoms in the short-term, while only surgical treatment

\footnotetext{
*Correspondence: sihags@mskcc.org

'Division of Thoracic Surgery, Massachusetts General Hospital, 55 Fruit Street,

Founders 7, Boston, Massachusetts 02114, USA

${ }^{4}$ Thoracic Surgery Service, Memorial Sloan Kettering Cancer Center, 1275

York Avenue, C-881, New York, NY 10065, USA

Full list of author information is available at the end of the article
}

via pulmonary thromboendarterectomy (PTE) offers the potential for cure [3].

PTE is a technically challenging operation that involves complete removal of organized fibrotic and thrombotic material from bilateral pulmonary arteries extending to segmental branches under intermittent deep hypothermic circulatory arrest [4]. The effectiveness of the operation is directly related to the location and accessibility of pulmonary arterial occlusive disease and the extent to which it is cleared by the surgeon [5] It is performed predominantly at a few experienced centers across the country, and these centers have been able to demonstrate excellent outcomes in appropriately selected patients. Thus far, the group at University of California San Diego Medical Center (UCSD) has reported the largest experience with PTE with an overall mortality rate of $4.9 \%$ and a mean decrease in pulmonary artery systolic pressures of $28 \mathrm{mmHg}$ correlating 
with a mean increase in cardiac output of $1.6 \mathrm{~L} / \mathrm{min}$. Reperfusion pulmonary edema was the most frequent postoperative complication at $10.9 \%$ [6]. In their more recent experience after completing 2700 cases, they reported a similarly substantial improvement in hemodynamics and cardiac function with an even lower mortality rate of $2.2 \%$ [7].

Our center initiated a program to surgically treat patients with CTEPH in 1998 as a product of a multidisciplinary collaboration between experts in pulmonary hypertension and cardiothoracic surgery. Since then, we have performed a total of 134 cases, and we have averaged 31 cases per year over the past 3 years, thereby becoming the only high volume center in PTE in our region. All patients were selected by a multi-disciplinary team led by an experienced pulmonologist in CTEPH, and all PTEs were performed jointly by a cardiac and thoracic attending surgeon. Here, we report our experience with building a CTEPH program and define a learning curve for surgeons interested in achieving proficiency in PTE.

\section{Methods}

All patients who underwent PTE from 1998 to 2016 at Massachusetts General Hospital in Boston, MA were retrospectively analyzed with the approval of the Partners Institutional Review Board Committee. A total of 134 patients were included in our study. Patients were selected for operation based on preoperative findings on pulmonary angiography, echocardiography, and nuclear ventilation-perfusion scans [8]. All cases were reviewed by a multi-disciplinary team of pulmonologists and cardiothoracic surgeons at our institution. PTE was performed jointly by a senior-level cardiac and thoracic attending surgeon in a manner similar to that described at UCSD [9]. A thoracic surgeon (CDW) performed or directly supervised all endarterectomies, and one of two cardiac surgeons assisted with cardiopulmonary bypass (GJV or MAV). Median sternotomy, cardiopulmonary bypass, aortic cross-clamping, hypothermia to 18 degrees ${ }^{\circ} \mathrm{C}$, and periods of circulatory arrest of up to 20 min for each side were all essential components of operative conduct for optimal exposure and clearance of pulmonary vasculature. Additional cardiac procedures were performed during the re-warming period if indicated. Preoperative hemodynamics were assessed during right heart catheterization, while postoperative hemodynamics were monitored via Swan-Ganz catheter (Edwards Life Sciences, Irvine, CA) in the operating room and intensive care unit. Of note, pulmonary capillary wedge pressures (PCWP) were not measured routinely in our intensive care unit postoperatively. All surgical, hemodynamic, and 30-day postoperative outcomes were recorded in our database.
For data review, patients were divided into 3 evenly distributed groups or terciles by case number. The first tercile (T1) $(n=44)$ spanned from October 1998 to September 2012 and represented a more sporadic experience that began ramping up in 2010. The second tercile (T2) $(n=45)$ extended from November 2012 to February 2015, and the third tercile (T3) $(n=45)$ from February 2015 to August 2016. Statistical comparisons between $\mathrm{T} 1$ and $\mathrm{T} 3$ were carried out using a two-tailed unpaired student's $t$ test for continuous variables, and a Chi-squared test for categorical variables. Significance was set at a threshold of $p<0.05$. We utilized STATA statistical software package, release 14 (StataCorp LP, College Station, TX) for all analyses.

To compute a learning curve, we plotted the cumulative running sum (CUSUM) of the difference of each value from the mean deep hypothermic circulatory arrest time across 134 consecutive cases, as this parameter improved dramatically with increasing surgeon experience. This methodology has been previously validated in the surgical literature for defining a learning curve for complex procedures $[10,11]$.

\section{Results}

We included all consecutive patients who underwent PTE since the inception of our institution's CTEPH program in $1998(n=134)$ and divided them into terciles (T1 - T3) to evaluate surgical, hemodynamic, and postoperative outcomes over time as our experience increased. Preoperative characteristics of all patients in our study are summarized in Table 1. Patients had an average age of 54 years, and $60 \%$ were male. The degree of pulmonary hypertension in these patients was severe with an average systolic pulmonary artery pressure (sPAP) of $78 \mathrm{mmHg}$ and diastolic pulmonary artery pressure (dPAP) of $28 \mathrm{mmHg}$. Mean pulmonary vascular resistance (PVR) was calculated at 639 dynes-sec- $\mathrm{cm}^{-5}$. Preoperatively, $87.3 \%$ of patients were classified as New York Heart Association (NYHA) Heart Failure Class II or III, and nearly all patients had either Jamieson type 2 or 3 disease (none had type 4 disease) [5]. These preoperative parameters did not vary significantly by tercile.

Postoperatively, we observed a mean decrease in SPAP of $41 \mathrm{mmHg}$ and a mean decrease in right atrial pressure (RAP) of $6 \mathrm{mmHg}$ overall (Table 2). The mPAP decreased from $49 \mathrm{mmHg}$ to $22 \mathrm{mmHg}$ overall, and there was no difference in the number of patients with residual pulmonary hypertension (mPAP $>30 \mathrm{mmHg}$ ) across terciles. These favorable hemodynamic results following PTE were achieved consistently across all 3 terciles of patients, and therefore increased surgeon experience did not appear to influence the degree of improvement in pulmonary artery pressures. Rather, patients with Jamieson type 2 disease had a significantly 
Table 1 Preoperative patient characteristics

\begin{tabular}{|c|c|c|c|c|c|}
\hline \multirow[b]{2}{*}{ Variable } & \multirow{2}{*}{$\begin{array}{l}\text { Overall } \\
(n=134)\end{array}$} & \multicolumn{3}{|l|}{ Tercile $(T)$} & \multirow{2}{*}{$\begin{array}{l}P \text { value } \\
\text { T1 vs. T3 }\end{array}$} \\
\hline & & $\mathrm{T} 1(n=44)$ & $\mathrm{T} 2(n=45)$ & $\mathrm{T} 3(n=45)$ & \\
\hline Age (y) & $54 \pm 15$ & $54 \pm 14$ & $54 \pm 14$ & $53 \pm 16$ & 0.757 \\
\hline Male Sex (\%) & $81(60.4)$ & $22(50.0)$ & $32(71.1)$ & $27(60.0)$ & 0.343 \\
\hline \multicolumn{6}{|l|}{ PAP $(\mathrm{mm} \mathrm{Hg})$} \\
\hline Systolic & $78 \pm 20$ & $77 \pm 19$ & $78 \pm 21$ & $78 \pm 20$ & 0.778 \\
\hline Diastolic & $28 \pm 9$ & $26 \pm 10$ & $30 \pm 8$ & $27 \pm 9$ & 0.882 \\
\hline PVR (dynes-sec-cm ${ }^{-5}$ ) & $639 \pm 373$ & $695 \pm 442$ & $618 \pm 371$ & $602 \pm 292$ & 0.243 \\
\hline $\mathrm{CO}(\mathrm{L} / \mathrm{min})$ & $4.7 \pm 1.5$ & $4.5 \pm 1.5$ & $4.8 \pm 1.4$ & $4.7 \pm 1.5$ & 0.531 \\
\hline DLCO (\% predicted) & $64 \pm 19$ & $66 \pm 17$ & $67 \pm 20$ & $56 \pm 18$ & 0.011 \\
\hline \multicolumn{6}{|l|}{ NYHA class } \\
\hline I & $1(0.7)$ & $0(0)$ & $1(2.2)$ & $0(0)$ & 0.218 \\
\hline$\|$ & $43(32.1)$ & 17 (38.6) & $14(31.1)$ & $12(26.7)$ & \\
\hline III & $74(55.2)$ & $21(47.7)$ & $26(57.8)$ & $27(60.0)$ & \\
\hline IV & $15(11.2)$ & $6(13.6)$ & $3(6.7)$ & $6(13.3)$ & \\
\hline \multicolumn{6}{|l|}{ Jamieson classification } \\
\hline Type 1 & $1(0.7)$ & $0(0)$ & $1(2.2)$ & $0(0)$ & 0.226 \\
\hline Type 2 & $64(47.8)$ & $24(54.5)$ & $20(44.4)$ & $20(44.4)$ & \\
\hline Type 3 & $61(45.5)$ & $20(45.5)$ & $17(37.8)$ & $24(53.3)$ & \\
\hline Type 4 & $0(0)$ & $0(0)$ & $0(0)$ & $0(0)$ & \\
\hline
\end{tabular}

Data are shown as mean \pm standard deviation or numbers (percentages)

PAP pulmonary artery pressure, PVR pulmonary vascular resistance, CO cardiac output, DLCO diffusing capacity of carbon monoxide, NYHA New York Heart Association

greater mean decrease in sPAP than patients with Jamieson type 3 disease ( 45 vs. $37, p=0.039$ ), further validating that anatomic and pathological classification of thromboembolic disease in the pulmonary arteries is a major predictor of outcome after PTE [5].

Similarly, mortality and other postoperative outcomes remained relatively consistent across our experience (Table 3). The 30-day mortality rate following PTE was $3.7 \%$ overall, which is on par with other high volume centers $[12,13]$. In the postoperative setting, $44.4 \%$ of patients experienced at least one complication, $20.8 \%$ of patients experienced a major complication, and $16.4 \%$ of patients experienced at least one pulmonary complication (Table 3). By far, the most common complication was atrial fibrillation at $29.7 \%$, and major complications included acute respiratory distress syndrome, pneumonia, or respiratory failure requiring re-intubation, sepsis, and return to the operating room for any reason. Though the

Table 2 Comparison of perioperative hemodynamic and surgical parameters

\begin{tabular}{|c|c|c|c|c|c|}
\hline \multirow[b]{2}{*}{ Variable } & \multirow{2}{*}{$\begin{array}{l}\text { Overall } \\
(n=134)\end{array}$} & \multicolumn{3}{|l|}{ Tercile $(T)$} & \multirow{2}{*}{$\begin{array}{l}P \text { value } \\
\text { T1 vs. T3 }\end{array}$} \\
\hline & & $\mathrm{T} 1(n=44)$ & $\mathrm{T} 2(n=45)$ & $\mathrm{T} 3(n=45)$ & \\
\hline \multicolumn{6}{|l|}{ Postoperative } \\
\hline sPAP $(m m ~ H g)$ & $37 \pm 13$ & $38 \pm 13$ & $35 \pm 13$ & $40 \pm 14$ & 0.468 \\
\hline mPAP (mm Hg) & $22 \pm 7$ & $21 \pm 6$ & $20 \pm 7$ & $23 \pm 8$ & 0.183 \\
\hline RAP (mm Hg) & $5 \pm 4$ & $5 \pm 3$ & $5 \pm 4$ & $5 \pm 3$ & 1.000 \\
\hline Mean $\Delta$ sPAP $(\mathrm{mm} \mathrm{Hg})$ & $41 \pm 21$ & $40 \pm 19$ & $43 \pm 22$ & $41 \pm 21$ & 0.908 \\
\hline Mean $\Delta$ mPAP $(\mathrm{mm} \mathrm{Hg})$ & $24 \pm 13$ & $25 \pm 11$ & $24 \pm 13$ & $24 \pm 14$ & 0.570 \\
\hline Mean $\triangle$ RAP $(\mathrm{mm} \mathrm{Hg})$ & $6 \pm 8$ & $7 \pm 11$ & $6 \pm 6$ & $5 \pm 6$ & 0.287 \\
\hline CPB time (min) & $180 \pm 41$ & $198 \pm 42$ & $182 \pm 42$ & $159 \pm 28$ & $<0.001$ \\
\hline Aortic cross-clamp time (min) & $132 \pm 31$ & $140 \pm 35$ & $134 \pm 28$ & $123 \pm 28$ & 0.018 \\
\hline DHCA time (min) & $37 \pm 15$ & $44 \pm 17$ & $35 \pm 13$ & $31 \pm 10$ & $<0.001$ \\
\hline
\end{tabular}

Data are shown as mean \pm standard deviation $s P A P$ systolic pulmonary artery pressure, $m P A P$ mean pulmonary artery pressure, $R A P$ right atrial pressure, $C P B$ cardiopulmonary bypass, $D H C A$ deep hypothermic circulatory arrest 
Table $\mathbf{3}$ Comparison of postoperative outcomes

\begin{tabular}{|c|c|c|c|c|c|}
\hline \multirow[b]{2}{*}{ Variable } & \multirow{2}{*}{$\begin{array}{l}\text { Overall } \\
(n=134)\end{array}$} & \multicolumn{3}{|l|}{ Tercile } & \multirow{2}{*}{$\begin{array}{l}P \text { value } \\
\text { T1 vs. T3 }\end{array}$} \\
\hline & & $\mathrm{T} 1(n=44)$ & $\mathrm{T} 2(n=45)$ & $\mathrm{T} 3(n=45)$ & \\
\hline 30-day mortality & $5(3.7)$ & $0(0)$ & $3(6.6)$ & $2(4.4)$ & 0.159 \\
\hline At least one complication & $72(44.4)$ & $28(63.6)$ & $17(37.8)$ & $27(60.0)$ & 0.724 \\
\hline At least one pulmonary complication & $19(14.8)$ & $5(11.4)$ & $7(15.6)$ & $7(15.6)$ & 0.563 \\
\hline At least one major complication & $26(20.3)$ & $11(25.0)$ & $9(20.0)$ & $6(13.3)$ & 0.162 \\
\hline Residual mPAP >30 mmHg & $11(8.2)$ & $4(9.1)$ & $4(8.9)$ & $3(6.7)$ & 0.671 \\
\hline 30-day readmission rate & $7(5.2)$ & $3(6.8)$ & $0(0)$ & $4(8.9)$ & 0.713 \\
\hline Length of hospital stay (d) & $12.6 \pm 9.0$ & $12.8 \pm 7.8$ & $13.0 \pm 11.7$ & $11.8 \pm 6.7$ & 0.517 \\
\hline Length of ICU stay (d) & $4.6 \pm 4.7$ & $4.5 \pm 3.4$ & $4.7 \pm 5.6$ & $4.6 \pm 4.8$ & 0.910 \\
\hline Duration on ventilator (d) & $2.0 \pm 3.0$ & $1.6 \pm 1.5$ & $2.6 \pm 4.5$ & $1.8 \pm 2.2$ & 0.618 \\
\hline
\end{tabular}

Data are shown as mean \pm standard deviation or numbers (percentages)

$I C U$ intensive care unit, MPAP mean pulmonary artery pressure

rate of major complications trended downward across terciles, this was not statistically significant. A total of 4 patients in our series had massive hemoptysis postoperatively, and there was no correlation with surgeon experience. The average length of hospital stay was 12.6 days, with an average of 4.6 days in the intensive care unit and 2.0 days on the ventilator. After undergoing PTE, $74.6 \%$ of patients had marked relief of their symptoms and were reclassified as NYHA class I from class II-IV, and $65 \%$ of patients in T1 were NYHA class I in comparison to $80 \%$ in $\mathrm{T} 3(p=0.15)$.

We did, however, detect a significant improvement in operative parameters with increased surgeon experience. Total cardiopulmonary bypass, aortic cross-clamp, and deep hypothermic circulatory arrest times steadily shortened from $\mathrm{T} 1$ to $\mathrm{T} 3$, and these differences were statistically significant (Table 2). Total cardiopulmonary bypass time decreased from a mean of $198 \mathrm{~min}$ to $159 \min (p<0.001)$ from $\mathrm{T} 1$ to $\mathrm{T} 3$, and total deep hypothermic circulatory arrest time decreased from a mean of $44 \mathrm{~min}$ to $31 \mathrm{~min}(p<0.001)$. In order to further illustrate a learning curve of PTE, Fig. 1 depicts a
CUSUM plot of deep hypothermic circulatory arrest times over 134 cases as compared to the mean value. Interestingly, two inflection points are seen in this curve at 22 and 95 cases. The first inflection point at 22 cases suggests a threshold of transitioning from novice to intermediate with PTE, as arrest times begin to trend downward thereafter. After the second inflection point at 95 cases, arrest times plummet even more steeply, indicating a threshold of attaining advanced expertise in clearing obstructed pulmonary arteries.

\section{Discussion}

All complex procedures are associated with a learning curve for surgeons, and PTE is among one of the more technically demanding operations in cardiothoracic surgery. It is undoubtedly a challenging procedure to learn, and our experience demonstrates that favorable outcomes can be achieved in the setting of a dedicated multi-disciplinary team of pulmonologists, surgeons, and intensivists working in concert to select appropriate patients, improve operative efficiency, and provide meticulous postoperative care. Accurate diagnosis of

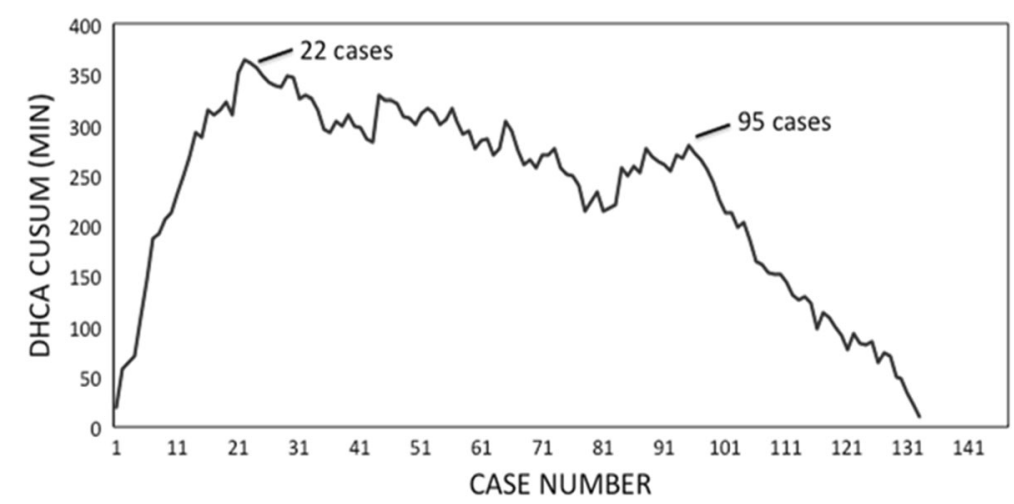

Fig. 1 CUSUM plot depicts learning curve for PTE. Cumulative running sum (CUSUM) of the difference in DHCA (deep hypothermic circulatory arrest) time from the mean value is plotted on the vertical axis vs. case number on the horizontal axis. Two inflection points are seen at 22 and 95 cases 
CTEPH and recognition of patients with disease amenable to surgical intervention are the first steps, and having the benefit of an expert pulmonologist in CTEPH as part of our team has greatly facilitated evaluation and subsequent referral of excellent surgical candidates. The other key components included the involvement of two senior-level cardiothoracic surgeons on each case, and 24-h coverage of our cardiothoracic surgery ICU by a certified intensivist. Even early in our program's existence, we were able to obtain adequate clearance of obstructed pulmonary arteries with significant postoperative hemodynamic improvements, despite much longer operative and circulatory arrest times. However, overall morbidity and mortality were not adversely affected during the initial phases of building our program, as there were no early deaths in our first 44 cases.

As we would expect, our learning curve suggests that operative efficiency is greatly enhanced with increasing case numbers. According to Fig. 1, approximately 20 cases are needed for a surgeon to become proficient at reliably recognizing and dissecting the thromboendarterectomy plane during circulatory arrest, while nearly 100 cases are needed to demonstrate mastery. To our knowledge, no other high volume center has described a learning curve for this procedure. The main limitation of our study is the fact that we have described the learning curve of a single team of providers at a single institution based on a retrospective analysis. We believe that the fundamental tenets that allowed us to successfully build our program, however, can be generalized and may prove useful to other programs early on in their trajectory. Surgical treatment of patients with CTEPH remains largely focused at regional centers of excellence at this time. As of 2013, only approximately 30 centers worldwide offered PTE surgery, and over half of cases were performed at the highest volume program at UCSD [14]. As CTEPH appears to be gaining prevalence in the U.S. and the limits of surgically curable disease are expanding [15-17], the need for more widespread access to PTE surgery is surely to arise in the future.

\section{Conclusions}

In summary, our experience offers other centers which aspire to build a multi-disciplinary program to treat CTEPH a road-map on how to achieve this goal. We conclude that adopting a team-based approach with an emphasis on proper patient selection and adequate surgical clearance of obstructed pulmonary arteries can lead to favorable outcomes from the outset. Operative expediency is largely a function of case volume, and may be less critical with respect to influencing surgical and hemodynamic outcomes.

\section{Abbreviations}

CTEPH: Chronic thromboembolic pulmonary hypertension;

CUSUM: Cumulative running sum; DHCA: Deep hypothermic circulatory arrest; dPAP: Diastolic pulmonary artery pressure; ICU: Intensive care unit; mPAP: Mean pulmonary artery pressure; NYHA: New York Heart Association; PAP: Pulmonary artery pressure; PCWP: Pulmonary capillary wedge pressure; PTE: Pulmonary thromboendarterectomy; PVR: Pulmonary vascular resistance; RAP: Right atrial pressure; SPAP: Systolic pulmonary artery pressure; T: Tercile

\section{Acknowledgements \\ None}

Funding

The authors have no sources of funding to disclose for this study.

Availability of data and materials

The full extent of the dataset analyzed during the current study are not publicly available due to patient privacy rights under the Health Information Portability and Accountability Act, but limited portions of our dataset may be made available from the corresponding author on reasonable request.

\section{Authors' contributions}

SS contributed to data analysis and wrote the bulk of the manuscript. BL contributed to cumulative running sum learning curve analysis. AW contributed to data collection and interpretation related to classification of pulmonary hypertension. JR contributed to data collection and interpretation related to classification of pulmonary hypertension. MV contributed to data collection and interpretation related to surgical outcomes. GV contributed to data collection and interpretation related to surgical outcomes. RC contributed to data interpretation and manuscript preparation. CW contributed to data collection, interpretation, and manuscript preparation. All authors have read and approved the final manuscript.

\section{Ethics approval and consent to participate}

Retrospective analysis of patient records was performed with the approval of the Partners Institutional Review Board Committee (Protocol \#2014P002212; Approved December 11, 2014), and specific patient consent was waived for this study.

\section{Consent for publication}

Not applicable.

\section{Competing interests}

The authors declare that they have no competing interests.

\section{Publisher's Note}

Springer Nature remains neutral with regard to jurisdictional claims in published maps and institutional affiliations.

\section{Author details}

${ }^{1}$ Division of Thoracic Surgery, Massachusetts General Hospital, 55 Fruit Street, Founders 7, Boston, Massachusetts 02114, USA. ${ }^{2}$ Division of Pulmonary and Critical Care Medicine, Massachusetts General Hospital, 55 Fruit Street, Boston, Massachusetts 02114, USA. ${ }^{3}$ Division of Cardiac Surgery, Massachusetts General Hospital, 55 Fruit Street, Cox 6, Boston, Massachusetts 02114, USA. ${ }^{4}$ Thoracic Surgery Service, Memorial Sloan Kettering Cancer Center, 1275 York Avenue, C-881, New York, NY 10065, USA.

Received: 4 June 2017 Accepted: 7 December 2017

Published online: 28 December 2017

\section{References}

1. Pengo $V$, Lensing AW, Prins MH, Marchiori A, Davidson BL, Tiozzo F, Albanese P, Biasiolo A, Pegoraro C, lliceto S, et al. Incidence of chronic thromboembolic pulmonary hypertension after pulmonary embolism. N Engl J Med. 2004;350:2257-64.

2. Riedel M, Stanek V, Widimsky J, Prerovsky I. Longterm follow-up of patients with pulmonary thromboembolism. Late prognosis and evolution of hemodynamic and respiratory data. Chest. 1982:81:151-8.

3. Ishida K, Masuda M, Tanabe N, Matsumiya G, Tatsumi K, Nakajima N. Long-term outcome after pulmonary endarterectomy for chronic thromboembolic pulmonary hypertension. J Thorac Cardiovasc Surg. 2012;144:321-6. 
4. Thistlethwaite PA, Kaneko K, Madani MM, Jamieson SW. Technique and outcomes of pulmonary endarterectomy surgery. Ann Thorac Cardiovasc Surg. 2008;14:274-82.

5. Thistlethwaite PA, Mo M, Madani MM, Deutsch R, Blanchard D, Kapelanski DP, Jamieson SW. Operative classification of thromboembolic disease determines outcome after pulmonary endarterectomy. J Thorac Cardiovasc Surg. 2002;124:1203-11.

6. Thistlethwaite PA, Madani M, Jamieson SW. Outcomes of pulmonary endarterectomy surgery. Semin Thorac Cardiovasc Surg. 2006;18:257-64.

7. Madani MM, Auger WR, Pretorius V, Sakakibara N, Kerr KM, Kim NH, Fedullo PF, Jamieson SW. Pulmonary endarterectomy: recent changes in a single institution's experience of more than 2,700 patients. Ann Thorac Surg. 2012;94:97-103. discussion 103

8. Witkin AS, Channick RN. Chronic Thromboembolic pulmonary hypertension: the end result of pulmonary embolism. Curr Cardiol Rep. 2015:17:63.

9. Jamieson SW, Kapelanski DP. Pulmonary endarterectomy. Curr Probl Surg. 2000;37:165-252.

10. Tapias $L F$, Morse CR. Minimally invasive Ivor Lewis esophagectomy: description of a learning curve. J Am Coll Surg. 2014;218:1130-40.

11. Chen PD, Wu CY, Hu RH, Chen CN, Yuan RH, Liang JT, Lai HS, Wu YM. Robotic major hepatectomy: Is there a learning curve? Surgery. 2017;161:642-9.

12. Mayer E, Jenkins D, Lindner J, D'Armini A, Kloek J, Meyns B, Ilkjaer LB, Klepetko W, Delcroix M, Lang I, et al. Surgical management and outcome of patients with chronic thromboembolic pulmonary hypertension: results from an international prospective registry. J Thorac Cardiovasc Surg. 2011:141:702-10.

13. Jamieson SW, Kapelanski DP, Sakakibara N, Manecke GR, Thistlethwaite PA, Kerr KM, Channick RN, Fedullo PF, Auger WR. Pulmonary endarterectomy: experience and lessons learned in 1,500 cases. Ann Thorac Surg. 2003;76: 1457-62. discussion 1462-1454

14. Ryan JJ, Rich S, Archer SL. Pulmonary endarterectomy surgery-a technically demanding cure for WHO Group IV Pulmonary Hypertension: requirements for centres of excellence and availability in Canada. Can J Cardiol. 2011;27:671-4.

15. Madani M, Mayer E, Fadel E, Jenkins DP. Pulmonary Endarterectomy. Patient selection, technical challenges, and outcomes. Ann Am Thorac Soc. 2016;13 Suppl 3:5240-7.

16. D'Armini AM, Morsolini M, Mattiucci G, Grazioli V, Pin M, Valentini A, Silvaggio G, Klersy C, Dore R. Pulmonary endarterectomy for distal chronic thromboembolic pulmonary hypertension. J Thorac Cardiovasc Surg. 2014;148:1005-11.

17. Jenkins DP, Biederman A, D'Armini AM, Dartevelle PG, Gan HL, Klepetko W, Lindner J, Mayer E, Madani MM. Operability assessment in CTEPH: lessons from the CHEST-1 study. J Thorac Cardiovasc Surg. 2016;152:669-674 e663.

\section{Submit your next manuscript to BioMed Central and we will help you at every step:}

- We accept pre-submission inquiries

- Our selector tool helps you to find the most relevant journal

- We provide round the clock customer support

- Convenient online submission

- Thorough peer review

- Inclusion in PubMed and all major indexing services

- Maximum visibility for your research

Submit your manuscript at www.biomedcentral.com/submit
Biomed Central 